\title{
Crowding Out Intrinsic Motivation in the Public Sector
}

\author{
Yannis Georgellis*, Elisabetta lossa ${ }^{\dagger \neq}$, Vurain Tabvuma* \\ ${ }^{*}$ Bournemouth University; ${ }^{\dagger}$ Brunel University; ${ }^{\ddagger}$ University of Rome Tor Vergata
}

\begin{abstract}
Employing intrinsically motivated individuals has been proposed as a means of improving public sector performance. In this article, we investigate whether intrinsic motivation affects the sorting of employees between the private and the public sectors, paying particular attention to whether extrinsic rewards crowd out intrinsic motivation. Using British longitudinal data, we find that individuals are attracted to the public sector by the intrinsic rather than the extrinsic rewards that the sector offers. We also find evidence supporting the intrinsic motivation crowding out hypothesis, in that, higher extrinsic rewards reduce the propensity of intrinsically motivated individuals to accept public sector employment. This is, however, only true for two segments of the UK public sector: the higher education sector and the National Health Service. Although our findings inform the literature on public service motivation, they also pose the question whether lower extrinsic rewards could increase the average quality of job matches in the public sector, thus improving performance without the need for high-powered incentives.
\end{abstract}

\section{INTRODUCTION}

Recent studies advocate that hiring individuals who are intrinsically, or public service motivated, is an effective way to improve performance and to overcome incentive problems in the public sector. As Crewson (1997) explains, employees who are intrinsically motivated tend to exhibit high levels of organizational commitment, increasing productivity and improving organizational performance. In a similar vein, Dilulio (1994) argues that public sector employees, presumably with higher levels of intrinsic motivation on average than private sector employees, are likely to report high satisfaction scores with intrinsic job characteristics and a high level of commitment to the organization they work for. Besley and Ghatak (2005) favor a sorting explanation, attributing the existence of a strong link

\footnotetext{
We would like to thank three anonymous reviewers for their constructive comments and suggestions. We are also grateful for helpful comments by Sarah Smith, Antonio Estache, Sophie Pommet, John Hunter, Jaideep Roy,

Konstantinos Pouliakas, Andrew Clark, and seminar participants at the Centre for Market and Public Organisation Workshop at Bristol University on "Public Services and Worker Motivation," the London School of Economics/ Integrating Cooperation Research across Europe Workshop on "When Financial Incentives Backfire: Crowding-Out Motivation at Work," and the European School for New Institutional Economics in Corsica. Address correspondence to the author at ygeorgellis@bournemouth.ac.uk.
}

doi:10.1093/jopart/muq073

(c) The Author 2010. Published by Oxford University Press on behalf of the Journal of Public Administration Research and Theory, Inc. All rights reserved. For permissions, please e-mail: journals.permissions@oup.com 
between intrinsic motivation and public sector performance to better job matching of agents and principals with similar dispositions, which reduces the need for high-powered incentives. Schneider (1987) and Bretz, Boudreau, and Judge (1994) lend credence to the sorting hypothesis by providing evidence consistent with the idea of individuals choosing organizations based on the similarity between their own dispositions and the characteristics of the organization.

Nevertheless, the empirical evidence on the validity of the sorting hypothesis, and whether intrinsic motivation and income are strong predictors of individuals' choice of employment between the public and the private sector, is not conclusive (Lewis and Frank 2002; Tschirhart et al. 2008; Wright and Christensen 2007). This is partly because the sorting process is confounded by the possibility that income and other extrinsic rewards could crowd out intrinsic motivation, deterring individuals with high levels of intrinsic motivation from joining the public sector. In fact, although higher monetary rewards increase the probability of filling a job vacancy, they often reduce the average quality of applicants as employees with lower levels of intrinsic motivation apply (Delfgaauw and Dur 2007, 2008).

In this article, we examine whether intrinsic motivation affects the allocation of employees between the private and the public sector, paying particular attention to whether extrinsic rewards cause a crowding out effect that alters the composition of the workforce in the two sectors. Accordingly, our analysis focuses on the sorting explanation of how extrinsic rewards crowd out intrinsic rewards rather than on how extrinsic rewards affect individuals' willingness to act prosocially (Frey 1992; Frey and Oberholzer-Gee 1997; Frey, Oberholzer-Gee, and Eichenberger 1996). Using data from the British Household Panel Survey (BHPS), a large-scale longitudinal survey that allows us to trace individuals' labor market histories, we estimate transition probabilities from the private into the public sector. Controlling for standard demographic and labor market characteristics, we assess the relative importance of intrinsic versus extrinsic rewards as determinants of individuals' decision to accept public sector employment, by including predicted earnings and domain satisfaction differentials between the two sectors as the main explanatory variables of interest.

Our results confirm that, in the context of the British labor market, higher predicted satisfaction with the nature of the work itself, our proxy for intrinsic motivation, increases individuals' propensity to make the transition from the private into the public sector. In contrast, higher predicted satisfaction with extrinsic job characteristics does not raise the probability of transition. These results imply that individuals are attracted to the public sector by the intrinsic rather than the extrinsic rewards that the sector offers, thus supporting the intrinsic motivation sorting hypothesis. Further, we find some evidence that extrinsic rewards in the public sector crowd out intrinsic motivation, in that, higher predicted earnings and satisfaction with the extrinsic job characteristics reduce individuals' propensity to accept employment in the public sector. However, such evidence is only found in the context of the higher education sector and the National Health Service. These findings shed a new light into the debate about whether a reduction of earnings and of other extrinsic rewards could improve the matching of employees with intrinsic motivation to public sector jobs and whether such a reduction could mitigate problems of adverse selection in public sector hiring. 


\section{RELATED LITERATURE}

The concept of public service motivation (PSM) has its roots in the public administration literature where it is defined as "an individual's predisposition to respond to motives grounded primarily or uniquely in public institutions" (Perry 1996). As a special case of prosocial motivation, manifested when individuals are in the public sector, the presence of PSM generates a number of implications. ${ }^{1}$ For instance, if values and sentiments associated with the public sector are attractive to individuals with PSM, hiring these individuals helps to overcome incentive problems in the public sector. Agents who care about the output will have less incentive to shirk in the public sector than in the private sector. As Francois (2001) argues, this is because public sector managers cannot commit in increasing other factors of production to maintain output when an agent shirks effort, whereas private sector managers can, due to the profit maximization motive. ${ }^{2}$ Likewise, individuals are more willing to donate labor in the public sector because the public sector can credibly commit not to expropriate labor. Gregg et al. (2008) found that workers in the nonprofit sector are 12 percentage points more likely to undertake unpaid overtime, which amounts to an equivalent of an extra 60,000 people working in the nonprofit sector in the United Kingdom.

Numerous empirical studies provide evidence of intrinsic motivation in the public sector. Early research shows that public sector managers are motivated by a high need for achievement and they place higher values on service to society as opposed to monetary rewards than private managers do (Guyot 1962; Kilpatrick, Cummings, and Jennings 1964; Warner et al. 1963). In the same spirit, Rainey (1982, 1997) shows that public sector employees exhibit a higher interest in altruistic behaviors when compared to private sector employees. More recently, Crewson (1997) finds that public sector employees rank intrinsic rewards higher than extrinsic rewards, whereas the opposite is true for private sector employees. Brewer and Selden (1998) find evidence of intrinsic motivation amongst whistleblowers, although their sample comprises only public sector employees, thus not allowing for a direct comparison with private sector employees. Other studies supporting the presence of intrinsic motivation among public sector employees include Lyons, Duxbury, and Higgins (2006), Dilulio (1994), Kim (2005), Houston (2000, 2006), and Feeney (2008). On the other hand, a number of studies have also shown that public and private sector employees assign equal values to intrinsic rewards and earnings or other extrinsic rewards (e.g., Lyons, Duxbury, and Higgins 2006; Maidani 1991). Recent studies, investigating the role that extrinsic rewards play in sorting individuals into different employment sectors, find that higher earnings are still preferred to lower earnings, even among individuals with PSM who can still value, and be motivated by, financial rewards (e.g., Alonso and Lewis 2001; Christensen and Wright 2009; Rainey 1982; Wittmer 1991; Wright 2007; Wright \& Pandey 2008; Vandenabeele 2008). Yet, whether it is the public sector causing individuals to exhibit behavior consistent with PSM or whether it is simply that public service motivated individuals who are drawn into the public sector remains an open empirical question.

1 There is a clear distinction in the literature between PSM or prosocial motivation and intrinsic motivation (see, e.g., Grant 2008; Perry et al. 2010). Although PSM could be viewed a special case of prosocial motivation, both PSM and prosocial motivation could be enhanced by the presence of intrinsic motivation.

2 See Francois and Vlassopoulos (2008) for a survey of literature that discusses the role of prosocial motivation in overcoming incentive problems in the provision of public goods. 
Studies investigating employee selection into the private and the public sector focus mostly on the sorting process driven by individuals' choice between highand low-powered incentives, that is, performance-related pay (PRP) versus fixed salary schemes. By and large, employees who are more productive select jobs that offer PRP schemes (Cadsby, Song, and Tapon 2007; Gerhart and Rynes 2003; Trevor, Gerhart, and Boudreau 1997). In contrast, less productive employees opt to work for organizations where earnings are not linked to performance (Harrison, Virick, and William 1996). Nevertheless, consistent with an increased emphasis in the literature on nonpecuniary job attributes as determinants of employee behavior, several studies investigate how intrinsic motivation influences individuals' decision to accept public sector employment. ${ }^{3}$ Largely, these studies confirm that intrinsic motivation, or PSM, predicts individuals' desire to work in the public sector (Lewis and Frank 2002; Tschirhart et al. 2008). For example, Lewis and Frank (2002) find that public sector employees have high levels of PSM, although its impact on choosing public sector employment is strongest for college graduates and teachers jobs than for public administration positions. Wright and Christensen (2007) show that although PSM does not predict that an individual's first job will be a public sector job, it increases the probability that future employment will be in the public sector. Gabris and Simo (1995) are a notable exception as they find that intrinsic motivation does not influence individuals' decision to work in the public sector, highlighting the complex interaction of a multitude of factors affecting individuals' sector choice decision. Such factors range from personal and work experiences to educational qualifications, employment contracts, earnings or other extrinsic rewards, and the availability of jobs. The complexity of the relationship between intrinsic motivation and extrinsic rewards is further confounded by the fact that what is often perceived to be a manifestation of PSM is simply a reflection of greater organizational commitment by employees who reciprocate when employers fulfill their obligations relating to pay, job security, and career development (Coyle-Shapiro and Kessler 2003).

In a related strand of the literature, as encapsulated by Motivation Crowding Out Theory, the emphasis has been placed on whether monetary incentives and other extrinsic rewards could undermine intrinsic motivation and the willingness of individuals to act prosocially. In his seminal book, The Gift Relationship: From Human Blood to Social Policy, Titmuss (1970) argues that paying for blood would decrease the supply of donated blood because monetary compensation would undermine social values. Following Titmuss, Deci (1971) finds that when money is used as an external reward, there is a decrease in intrinsic motivation, whereas verbal reinforcement and positive feedback increases intrinsic motivation. Lepper, Greene, and Nisbett (1973) find that among children, extrinsic rewards reduce intrinsic motivation. Building upon these findings, studies show that the introduction of monetary rewards for certain tasks has negative consequences on intrinsic motivation (Deci, Koestner, and Ryan 1999; Deci and Ryan 1985; Houston 2006; Ryan and Deci 2000). Carpenter and Myers (2007) find that altruism and reputational concerns are positively related to individuals' volunteering to be fire fighters. They also find that the positive effect of monetary incentives on volunteering declines with reputational concerns,

3 Research findings suggest that employee behavior, including turnover behavior, is most likely to be influenced by employees' satisfaction with nonpecuniary job attributes such as meeting expectations regarding career opportunities, relationships with coworkers, and working conditions and less likely to be influenced by matching of individual and organizational values (Moynihan and Pandey 2008; and Vigoda and Cohen 2003). 
establishing a strong link between extrinsic incentives and employee sorting into a prosocial sector. $^{4}$

However, evidence also shows that extrinsic rewards do not necessarily reduce intrinsic motivation, pointing toward a more critical conceptualization of the motivation crowding-out hypothesis. Such a conceptualization acknowledges that the effect of rewards is determined by the nature of the task being performed and highlights the importance of other determinants of behavior such as self-efficacy and the nature of the motives themselves (Bandura 1977; Bartol and Locke 2000; Frese and Fay 2001; Locke and Henne 1986; Locke and Latham 1990; Thierry 1990). Reward procedures for poorly defined performance result in lower intrinsic motivation, whereas reward procedures requiring specific task performance that signal personal or social significance result in increased intrinsic motivation (Eisenburger, Pierce, and Cameron, 1999; Wiersma 1992). Given that many tasks in prosocial public sector jobs are nonverifiable and effort is unobservable, high extrinsic rewards are likely to result in lower intrinsic motivation.

Against this background, we develop theoretical arguments to explain why and how intrinsic motivation could influence the sorting of workers between the private and the public sectors. We also explain why extrinsic rewards could undermine the willingness of intrinsically motivated individuals to accept employment in the public sector.

\section{THEORETICAL FOUNDATIONS}

To develop our theoretical arguments on how intrinsic motivation affects the sorting of workers between the private and public sectors, we assume that rational individuals make the transition into the new sector by anticipating that the utility from the new job outweighs the utility from their current job. Although there are strong arguments against rationality, most notably Simon (1957), recent empirical findings have shown that job satisfaction, a proxy for utility, in the year prior to a job change is a strong predictor of when an individual will choose to change jobs (Clark, Georgellis, and Sanfey 1998), thus improving the plausibility of the assumption that individuals can reasonably anticipate the future utility they will derive from a new job. We further argue that individuals derive positive utility from both intrinsic (prosocial) and extrinsic job aspects, as well as from their reputation for being prosocial. Assuming that the public sector offers more opportunities for individuals to carry out altruistic and prosocial actions, individuals who assign high values to these activities will derive higher utility from working in the public sector and therefore will be more likely to be attracted into public sector employment. Evidently, the utility that individuals derive from working in the public sector and the weights they assign to prosocial and reputational effects depend on their underlying motives for seeking public sector employment. In the public administration literature, PSM reflects three main categories of motives: rational, norm based, and affective. Rational motives are present when individuals want to participate in policy making to pursue their political agenda or when individuals commit to a public program because they personally identify with it. Norm-based motives are generated by a desire to pursue the public interest; they include patriotism, civic duty,

4 See Frey and Jegen (2001) for a literature survey on motivation crowding theory. Studies that examine the link between extrinsic rewards and individuals' propensity to act prosocially include Frey, Oberholzer-Gee, and Eichenberger (1996), Frey and Oberholzer-Gee (1997), Gneezy and Rustichini (2000a, 2000b), Benabou and Tirole (2006), and Ariely, Bracha and Meier (2009). 
and a sense of loyalty to the government. Affective motives refer to behavior motivated by emotional responses to different social contexts and they are characterized by a desire to help others. This predisposition is determined by environmental factors, such as parental modeling or socialization within organizations.

To formalize these arguments, we borrow from Benabou and Tirole (2006) (hereafter BT) to provide a simple theoretical framework. ${ }^{5}$ We consider the behavior of agents who choose to work in the public sector. $a_{k}$ denotes the level of prosocial activities undertaken by each agent in sector $k$ at cost $c a_{\mathrm{k}}$ and $y_{k}$ denotes the (vector of) extrinsic rewards, enjoyed by agents in sector $k, k=P, G$, where $k=P$ denotes the private sector and $k=G$ denotes the public sector. Extrinsic rewards include wages, job security, and working hours. $\hat{a} \equiv a_{G}-a_{P}$ denotes the difference in prosocial activities between the public and the private sector, whereas $\hat{y} \equiv y_{G}-y_{P}$ denotes the differential in extrinsic rewards. We take $a_{k}$ as given and assume that more prosocial activities are carried out in the public sector so that $\hat{a}>0$. The sector in which an agent works, the level of prosocial activities $a_{k}$, and the extrinsic rewards $y_{k}$ are publicly observable.

Agents differ in two dimensions: their intrinsic valuation for prosocial activities and their valuation for extrinsic rewards. An agent's type is then defined by the intrinsic value $\omega_{i} \in[\underline{\omega}, \bar{\omega}]$ that he attaches to carrying out 1 unit of prosocial activities, where $\underline{\omega}$ may be negative to indicate that an individual may dislike prosocial activities and by the value $\chi_{i} \in[\chi, \bar{\chi}]$ that he attaches to enjoying 1 unit (in monetary units) of extrinsic rewards; $\omega_{i}$ and $\chi_{i}$ are random variables with cumulative distribution function $H\left(\omega_{i}, \chi_{i}\right)$.

Agents have reputational concerns and wish to appear prosocial/altruistic. The value of reputation depends linearly on the posterior belief $E_{\omega}\left(\omega_{i} \mid \hat{a}, \hat{y}, k\right)$ of the agent's type $\omega_{i}$, given the sector $k$ in which the agent works, the differential $\hat{a}$ in the level of prosocial activity between the two sectors, and the differential $\hat{y}$ in extrinsic rewards between the two sectors. The utility of agent $i$ from working in sector $k$ is

$$
U_{i, k}=\left(\omega_{i}-c\right) a_{k}+\chi_{i} y_{k}+\mu_{i} E_{\omega i}\left(\omega_{i} \mid \hat{a}, \hat{y}, k\right),
$$

where $\mu_{i} \in[0,1]$ is the weight on reputational concerns, which may change across individuals.

Initially, agents are randomly allocated between the private and the public sector. On the job, agents privately learn their type $\theta=\left\{\omega_{i}, \chi_{i}\right\}$ and choose whether to remain in the sector they are in or to move to the other sector, given $a_{k}$ and $y_{k}$. Types in the private sector for whom $U_{i, G} \geq U_{i, P}$ will move to the public sector; types in the public sector for whom $U_{i, G}<U_{i, P}$ will move to the private sector. Over time, therefore, types will separate between sectors: those (referred to as "the highly intrinsically motivated") for whom

$$
\omega_{i} \hat{a}+\chi_{i} \hat{y} \geq \tilde{\omega}_{i} \equiv c \hat{a}-\mu_{i} R(\hat{a}, \hat{y}),
$$

where

$$
R(\hat{a}, \hat{y}) \equiv E_{\omega i}\left(\omega_{i} \mid \hat{a}, \hat{y}, G\right)-E_{\omega i}(\omega i \mid \hat{a}, \hat{y}, P)
$$


will be in the public sector, whereas those with low intrinsic motivation, $\omega_{i}<\tilde{\omega}_{i}$, will be in the private sector; $R(\hat{a}, \hat{y})$ denotes the reputational gain from working in the public sector compared to the private sector.

Since initially half of the agents are in the private sector, the probability of transition from the private to the public sector is

$$
p(\hat{a}, \hat{y}, \mu)=\frac{1}{2} \operatorname{Pr}\left(\omega_{i} \hat{a}+\chi_{i} \hat{y} \geq \tilde{\omega}_{i}\right) .
$$

Within this framework, BT shows as follows:

1. Intrinsic motivation for prosocial activities is an important factor explaining why people wish to participate in prosocial activities. We add it that, to the extent that more activities are carried out in the public sectors, intrinsic motivation helps explaining the desire of people to work in the public sector. Other things equal, people with higher intrinsic motivation wish the most to join the public sector.

2. The greater the level of prosocial activities carried out in the public sector compared to the private sector (and thus $\hat{a}$ ), the more intrinsically motivated people wish to move to the public sector.

3. For a given level of prosocial activities in the public sector (and thus $\hat{a}$ ), an increase in extrinsic rewards in the public sector $(d \hat{y}>0)$ may reduce the reputational gain $R(\hat{a}, \hat{y})$ from working in the public sector. Intuitively, as observers cannot observe agents' types, a signal extraction problem arises and an increase in extrinsic rewards generates two effects on reputation. First, new types are drawn to the public sector (i.e., $\tilde{\omega}_{i}$ decreases). The new composition of the public sector thus comprises fewer intrinsically motivated agents and the "good reputation" of working in the public sector decreases (as the new members have lower $\omega_{i}$ 's than the old one, they drag down the group reputation for prosocial orientation). However, the stigma of working in the private sector also increases (as the members with high $\omega_{i}$ 's move to the public sector). As such, the reputational gain $R(\hat{a}, \hat{y})$ of working in the public sector may increase or decrease (this is the "image spoiling effect of extrinsic rewards").

4. Because of (3), an increase in extrinsic rewards in the public sector $(d \hat{y}>0)$ may crowd out intrinsic motivation, in the sense that it may reduce the number of agents who wish to work in the public sector $\left(d \tilde{\omega}_{i}>0\right)$.

5. To the extent that women care more about their reputation for prosocial activities than men, crowding out is more likely to occur for women than for men.

\section{DATA AND METHODOLOGY}

\section{Data}

We use data from the first 14 waves of the BHPS covering the period 1991-2004, providing a rich source of information on demographic and labor market characteristics, as well as information on individuals' subjective evaluation of their jobs and their economic situation. The BHPS is an annual survey consisting of a nationally representative sample of about 
5,500 households recruited in 1991, containing approximately 10,000 individuals. The sample is a stratified clustered design drawn from the Postcode Address File. All residents present at those addresses at the first wave of the survey were reinterviewed each successive year, and they were followed even if they moved to a new household. The BHPS is an unbalanced panel in that, although approximately 10,000 individuals are interviewed year to year, some individuals drop out from the sample. Due to attrition, men remain in the survey for an average of 4.8 years, whereas women remain in the sample for 4.1 years. $^{6}$

We restrict our sample to full-time workers, between the ages of 16 and 65 . This yields 37,384 and 25,728 person-year observations for men and women, respectively. Crucially, the panel nature of the data allows us to identify 747 transitions from the private to the public sector during the sample period. All these transitions were initiated voluntarily by the employees themselves (i.e., quits), with no intervening unemployment or inactivity spells. Our sample does not include observations of individuals that move from full-time to part-time jobs or from part-time to full-time jobs.

\section{Measures}

In order to make the distinction between intrinsic and extrinsic rewards operational, we classify wages, job security, and hours of work as extrinsic rewards. To proxy the utility that individuals derive from intrinsic rewards, we follow Pouliakas and Theodossiou (2009) and use responses to the question about "satisfaction with the nature of the work itself," available in the BHPS data. Nevertheless, it should be noted that this is not the only proxy for measuring intrinsic motivation in the literature nor is it a sufficient proxy for measuring PSM. Perry (1996) proxies PSM by survey questions focusing on attraction to policy making, commitment to public interest, compassion, and self-sacrifice. Crewson (1997), Lewis and Frank (2002), and Tschirhart et al. (2008) use responses to a question on the importance of "working in a job that allows one to help other people and a job that is useful to society," whereas Feeney (2008) uses responses to the question about the importance of "... the ability to serve the public and the public interest ... in making your decision to take a job at your current organization." Ideally, we would like to use measures that incorporate an element of altruistic, prosocial or other regarding behavior, but such measures are not available in the BHPS (Perry and Hondeghem 2008; Steen 2006, 2008).

To proxy the utility derived from extrinsic rewards, we use real wages, satisfaction with job security, and satisfaction with working hours. ${ }^{7}$ Overall and domain satisfaction variables are measured on an ordinal scale 1 to 7 where a value of 1 corresponds to not satisfied at all and a value of 7 corresponds to completely satisfied. The responses are constructed from individuals' responses to the question: "I am going to read out a list

6 For a detailed description of the BHPS survey, including details about survey design, attrition, and sampling issues, see Lynn (2006). Uhrig (2008) provides a detailed analysis of attrition patterns in the BHPS.

7 Throughout our empirical analysis, we consider individuals to have a predetermined level of intrinsic motivation, which is the result of environmental factors such as parental modeling and socialization within social groups that individuals belong to. Because it is difficult to measure individuals' motives directly, we proxy such motives by using self-reported domain job satisfaction scores. Numerous studies have validated the use of self-reported satisfaction measures. For example, it has been shown that job satisfaction predicts future quits (Clark, Georgellis, and Sanfey 1998; Freeman 1978) and it is positively correlated with productivity (Mangione and Quinn 1975). See Diener (2000) for a review. 
Table 1

The Distribution of Job Satisfaction Measures

\begin{tabular}{|c|c|c|c|c|c|c|c|c|}
\hline \multirow[b]{2}{*}{$\underline{\text { Rank }}$} & \multicolumn{2}{|c|}{$\begin{array}{l}\text { Overall Job } \\
\text { Satisfaction }\end{array}$} & \multicolumn{2}{|c|}{$\begin{array}{l}\text { Satisfaction with } \\
\text { the Work Itself }\end{array}$} & \multicolumn{2}{|c|}{$\begin{array}{c}\text { Satisfaction with } \\
\text { Job Security }\end{array}$} & \multicolumn{2}{|c|}{$\begin{array}{l}\text { Satisfaction with } \\
\text { Hours Worked }\end{array}$} \\
\hline & Count & $\%$ & Count & $\%$ & Count & $\%$ & Count & $\%$ \\
\hline \multicolumn{9}{|l|}{ Males } \\
\hline 1 & 684 & 1.92 & 685 & 1.92 & 1,463 & 4.12 & 977 & 2.74 \\
\hline 2 & 1,150 & 3.23 & 995 & 2.79 & 1,290 & 3.63 & 1,328 & 3.73 \\
\hline 3 & 2,837 & 7.97 & 2,377 & 6.68 & 2,871 & 8.08 & 3,973 & 11.16 \\
\hline 4 & 3,511 & 9.86 & 3,318 & 9.32 & 3,639 & 10.24 & 4,724 & 13.27 \\
\hline 5 & 8,502 & 23.88 & 7,588 & 21.31 & 6,746 & 18.98 & 8,003 & 22.47 \\
\hline 6 & 15,223 & 42.76 & 14,614 & 41.05 & 12,365 & 34.79 & 12,282 & 34.49 \\
\hline 7 & 3,693 & 10.37 & 6,027 & 16.93 & 7,166 & 20.16 & 4,324 & 12.14 \\
\hline Total & 35,600 & 100.00 & 35,604 & 100.00 & 35,540 & 100.00 & 35,611 & 100.00 \\
\hline \multicolumn{9}{|c|}{ Females } \\
\hline 1 & 444 & 1.75 & 449 & 1.77 & 868 & 3.42 & 542 & 2.13 \\
\hline 2 & 708 & 2.79 & 673 & 2.65 & 655 & 2.58 & 785 & 3.09 \\
\hline 3 & 1,691 & 6.66 & 1,608 & 6.33 & 1,700 & 6.70 & 2,930 & 11.53 \\
\hline 4 & 1,642 & 6.47 & 1,712 & 6.74 & 1,828 & 7.21 & 2,369 & 9.32 \\
\hline 5 & 5,566 & 21.92 & 5,206 & 20.49 & 4,308 & 16.99 & 5,718 & 22.51 \\
\hline 6 & 11,803 & 46.48 & 10,819 & 42.58 & 9,478 & 37.38 & 9,284 & 36.54 \\
\hline 7 & 3,542 & 13.95 & 4,939 & 19.44 & 6,519 & 25.71 & 3,777 & 14.87 \\
\hline Total & 25,396 & 100.00 & 25,406 & 100.00 & 25,356 & 100.00 & 25,405 & 100.00 \\
\hline
\end{tabular}

of various aspects of jobs, and after each one I'd like you to tell me from this card (19) which number best describes how satisfied or dissatisfied you are with that particular aspect of your present job." Table 1 summarizes the distribution of the overall and domain satisfaction measures used in our analysis.

\section{Methodology}

The aim of the empirical analysis is to uncover the factors affecting individuals' decision to accept public sector employment. To this end, we estimate transition probabilities into the public sector assuming that private sector employees at time $t-1$ will accept employment in the public sector at time $t$, if the expected extrinsic and intrinsic rewards in the new job exceed those in the current job. However, although rewards in the current job, at time $t-1$, are observable, expected rewards in the future public sector job, at time $t$, are unobservable, posing the question of how best to proxy such future rewards. A common approach used in the literature is to predict employees' expected rewards should they join the public sector based on the rewards of those with similar productive characteristics who are currently public sector employees. ${ }^{8}$ Adopting this approach, we estimate the expected future rewards

8 Quite often, public sector workers with similar characteristics happen to be family members or friends who can provide information and knowledge about pecuniary and nonpecuniary aspects of employment in the public sector. Indeed, Clerkin, Paynter, and Sheen (2009) and Lewis and Frank (2002) find that employees' decision to accept employment in the public sector is often informed and influenced by family members or friends in the public sector. Arguably, the availability of such information and knowledge prior to the transition into public sector employment could also help mitigate the potential problem of cognitive dissonance following the transition. 
in the public sector using information from the sample of public sector workers observed in our data. In the case of earnings, for example, we regress earnings against personal, demographic, and other productive characteristics using the sample of public sector workers. The estimated coefficients represent the earnings returns to these characteristics in the public sector, which current private sector workers should expect to enjoy should they make the transition into the public sector. In a similar fashion, we estimate the predicted domain satisfaction scores in the public sector based on the sample of current public sector employees.

Nevertheless, a caveat of such an approach is that the observed sample of public sector employees could be nonrandom in that unobservable employee characteristics that affect the rewards in that sector could be correlated with the decision to accept employment in the sector. For example, unobserved ability could affect earnings in the private and public sectors and at the same time affect the choice of a public sector job over a private sector one. This leaves open the possibility that the observed sample of public sector employees in our data is a nonrandomly selected sample, in that it might include employees who joined the public sector simply because should they be private sector employees they will be earning low wages. To control for such potential sample selection bias when estimating predicted earnings and job satisfaction differentials, we use Heckman's (1979) two-step selectivity correction method. ${ }^{9}$

Using the estimated coefficients from the earnings equations, we calculate predicted earnings differentials between the public and private sector, $\hat{y}_{i t}=\hat{y}_{i t}^{G}-\hat{y}_{i t}^{P}$. In a similar fashion, we estimate predicted differentials for satisfaction with job security, $\hat{S}_{i t(\mathrm{SEC})}=\hat{S}_{i t(\mathrm{SEC})}^{G}-\hat{S}_{i t(\mathrm{SEC})}^{P}$, satisfaction with hours worked $\hat{S}_{i t(\mathrm{HRS})}=\hat{S}_{i t(\mathrm{HRS})}^{G}-\hat{S}_{\hat{S}^{P}} \hat{S}^{\mathrm{G}(\mathrm{HRS})}$, and satisfaction with the work itself (an intrinsic reward) $\hat{S}_{i t(\text { WORK })}=\hat{S}_{i t(\text { WORK })}^{G}-\hat{S}_{i t(\text { WORK })}$ between the public and private sectors. These predicted earnings and domain satisfaction differentials enter as additional regressors in the private to public sector transition equation:

$$
\operatorname{Pr}\left(M_{i t}^{G}=1\right)=\alpha_{0}+\alpha_{1} \hat{y}_{i t}+\alpha_{2} \hat{S}_{i t(\mathrm{SEC})}+\alpha_{3} \hat{S}_{i t(\mathrm{HRS})}+\alpha_{4} \hat{S}_{i t(\mathrm{WORK})}+\beta^{\prime} X_{i, t-1}^{P}+\epsilon_{i t} .
$$

where $M_{i t}^{G}$ is an observed indicator variable taking the value 1 if an individual $i$ moves into the public sector at time $t$ and 0 otherwise. The vector $X_{i, t-1}^{P}$ represents individual and labor market characteristics at time $t-1$, the year prior to making the transition. $\epsilon_{i t}$ is a random error term.

The main hypothesis that intrinsic motivation increases the probability of transition into the public sector implies a positive and significant coefficient $\alpha_{4}$. If extrinsic rewards exert little or no influence on individuals' decision to enter the public sector, then the coefficients $\alpha_{1}$ to $\alpha_{3}$ will be statistically insignificant. Negative and statistically significant coefficients $\alpha_{1}$ to $\alpha_{3}$ are consistent with the crowding out hypothesis, whereby extrinsic rewards mitigate an individual's utility from the intrinsic rewards associated with the transition into the public sector.

We expand on our analysis by testing our hypothesis on transitions from the public to the private sector. This will allow us to gain a comparative perspective of the motivations for transition between the two sectors. In this case, we calculate $\hat{y}_{i t}=\hat{y}_{i t}^{G}-\hat{y}_{i t}^{P}$. We use the same procedure for the satisfaction differentials. We further test the hypothesis for 
Table 2

Number of Observations of Transitions

\begin{tabular}{lll}
\hline & \multicolumn{2}{c}{ Observations } \\
\cline { 2 - 3 } & Males & Females \\
\hline Entry into Public Sector from Private Sector & 336 & 411 \\
Entry into Caring Public Sector & 59 & 185 \\
Entry into Noncaring Public Sector & 162 & 95 \\
Entry into Private Sector from Public Sector & 349 & 310 \\
Entry into Caring Private Sector & 24 & 86 \\
Entry into Noncaring Private Sector & 241 & 135 \\
\hline
\end{tabular}

Note: Not all individuals that make the transition from the public to the private sector and from the private sector to the public sector provide information on their occupations, which we use to identify caring and noncaring jobs. This is why lines 2 and 3 do not add up to line 1 , and lines 5 and 6 do not add up to line 4 .

transitions into caring and noncaring jobs and transition into different government subsectors. ${ }^{10}$ Finally, we investigate whether individuals' motives to move into the public sector are different for high earners from those of low earners.

\section{RESULTS}

Table 2 reports the number of transitions between the private and the public sectors, distinguishing also between caring and noncaring jobs. We observe that among the women who accepted employment in the public sector, the majority entered into caring jobs rather than noncaring jobs. This is the opposite for men entering into the public sector, with more men entering into noncaring jobs than caring jobs. As far as transitions into the private sector are concerned, employees who leave the public sector to accept private sector jobs tend to enter into noncaring jobs. Taking the view that the public sector offers more opportunities to carry out prosocial actions, these stylized facts are consistent with the ample evidence in the literature suggesting the presence of important gender differences in prosocial motivation (Croson and Gneezy 2009). As Benabou and Tirole (2006) argue, if indeed women assign higher weights on prosocial reputational concerns than men, then women are more likely to contribute more prosocial actions in the absence of extrinsic rewards and women will also be more likely respond more negatively than men to extrinsic rewards. When studying the willingness to donate blood, Mellstrom and Johannesson (2008) find similar evidence in that in the absence of monetary incentives women donate more blood than men do. However, when monetary incentives are introduced, the blood donations of women drop significantly. When subjects are offered the choice to give the monetary payment to charity, the blood donations of women increase back to levels when there were no monetary incentives. The blood donations of men remain approximately the same throughout.

Table 3 shows that on average the public sector has higher extrinsic rewards than the private sector. The real wage is on average significantly higher in the public sector than in the private sector for both men and women. Working hours are significantly less in the public sector than in the private sector (for both men and women). Public sector workers 
Table 3

Gender and Sector Means for Real Wage, Hours Worked, and Job Tenure

\begin{tabular}{|c|c|c|c|}
\hline & \multicolumn{2}{|c|}{ Means } & \multirow{2}{*}{$\begin{array}{c}T \text {-stat on Sector } \\
\text { Difference }\end{array}$} \\
\hline & Public & Private & \\
\hline \multicolumn{4}{|c|}{ Real wage (£/month) } \\
\hline Men & 1,848 & 1,688 & $10.69 * * *$ \\
\hline Women & 1,494 & 1,131 & $34.19 * * *$ \\
\hline \multicolumn{4}{|c|}{ Hours worked (weekly) } \\
\hline Men & 38.72 & 40.68 & $-22.02 * * *$ \\
\hline Women & 35.83 & 37.09 & $-17.79 * * *$ \\
\hline \multicolumn{4}{|c|}{ Job tenure (years) } \\
\hline Men & 6.42 & 4.56 & $21.25 * * *$ \\
\hline Women & 4.99 & 3.45 & $22.02 * * *$ \\
\hline
\end{tabular}

(both men and women) have significantly longer job tenure than private sector workers, consistent with the view that the public sector offers better job security than the private sector (see, e.g., Bender 1998). These results are important because they confirm the commonly held belief that, in the context of the British labor market, the public sector offers higher extrinsic rewards on average than the private sector, which means that there is scope for the above theoretical model and its predictions. That is, the public sector having higher extrinsic rewards may reduce the reputational (for being prosocial) benefit for making the transition to the public sector. This is because the high extrinsic rewards make it harder to differentiate whether an individual's motive for moving to the public sector is to fulfill prosocial motivations or to satisfy extrinsic desires.

Turning to the main set of results, table 4 shows the estimated probit coefficients of the transition equations from the private to the public sector, separately for men and women.

As the estimated coefficients in table 4 suggest, there is strong evidence in support of the main hypothesis that individuals are more likely to move into the public sector when they expect to enjoy greater satisfaction with the nature of the work itself. Furthermore, for both men and women, higher predicted real wages in the public sector reduce the probability of moving into the public sector, consistent with the image spoiling effect of monetary rewards. The satisfaction with job security and working hours differentials are also negative and significant for men. Thus, the results offer broad support for the hypothesis that high extrinsic public sector rewards reduce the probability of intrinsically motivated men moving into the sector. However, although the satisfaction with working hours differential is negative and significant, the satisfaction with job security is positive and significant for women, which highlights the importance of job security as a strong predictor for women's decision to accept a public sector job. In contrast, men are less likely than women to join the public sector out of a desire for greater job security, perhaps because they are facing much less labor market discrimination. Overall, the results of the predicted real wage and satisfaction with working hours differentials are consistent with the crowding out hypothesis whereby extrinsic rewards mitigate an individual's utility from the intrinsic rewards associated with the transition into the public sector. This grouping of results shows that individuals who are intrinsically or public service motivated join the public sector 
Table 4

Probit Results for Transition into Public and Private Sectors

\begin{tabular}{|c|c|c|c|c|}
\hline & \multicolumn{2}{|c|}{ Public } & \multicolumn{2}{|c|}{ Private } \\
\hline & Males & Females & Males & Females \\
\hline$\hat{y}_{i t}$ & $-2.148^{* * *}(0.706)$ & $-1.269 * * *(0.437)$ & $-1.063(0.876)$ & $1.514 * *(0.594)$ \\
\hline$\hat{s}_{i t(S E C)}$ & $-0.470 * *(0.184)$ & $0.347 * *(0.166)$ & $0.123(0.219)$ & $0.315(0.244)$ \\
\hline$\hat{s}_{i t(\mathrm{WORK})}$ & $0.579 * * *(0.213)$ & $0.890^{* * *}(0.331)$ & $0.067(0.242)$ & $-0.089(0.468)$ \\
\hline$\hat{s}_{i t(\mathrm{HOURS})}$ & $-0.937 * * *(0.283)$ & $-0.608^{* *}(0.244)$ & $-0.032(0.335)$ & $0.611 *(0.360)$ \\
\hline $\begin{array}{l}\text { Employer offers } \\
\text { pension }(t)\end{array}$ & $0.239(0.151)$ & $0.192(0.143)$ & $0.343 *(0.185)$ & $-0.201(0.188)$ \\
\hline Age $(t-1)$ & $0.001(0.003)$ & $0.001(0.005)$ & $-0.007 *(0.004)$ & $-0.012 *(0.006)$ \\
\hline Pension $(t-1)$ & $-0.220 * * *(0.060)$ & $-0.267 * * *(0.062)$ & $-0.409 * * *(0.079)$ & $-0.342 * * *(0.077)$ \\
\hline $\begin{array}{l}\text { Trade union } \\
\text { member }(t-1)\end{array}$ & $-0.068(0.076)$ & $0.234 * * *(0.077)$ & $0.035(0.082)$ & $0.209 * *(0.083)$ \\
\hline Married $(t-1)$ & $-0.254 * * *(0.086)$ & $-0.237 * * *(0.086)$ & $-0.061(0.099)$ & $-0.121(0.109)$ \\
\hline $\begin{array}{l}\text { Living as couple } \\
(t-1)\end{array}$ & $-0.128(0.087)$ & $-0.215^{* * *}(0.081)$ & $-0.103(0.110)$ & $0.065(0.102)$ \\
\hline $\begin{array}{l}\text { Widowed } \\
(t-1)\end{array}$ & $0.076(0.437)$ & $-0.367(0.333)$ & $0.021(0.509)$ & $-0.363(0.332)$ \\
\hline Divorced $(t-1)$ & $0.145(0.164)$ & $-0.128(0.129)$ & $-0.122(0.189)$ & $-0.020(0.149)$ \\
\hline $\begin{array}{l}\text { Higher level } \\
\text { education } \\
(t-1)\end{array}$ & $0.058(0.079)$ & $0.274 * *(0.110)$ & $-0.132(0.101)$ & $-0.221(0.153)$ \\
\hline $\begin{array}{l}\text { Medium-level } \\
\text { education } \\
(t-1)\end{array}$ & $0.074(0.071)$ & $0.172 * *(0.088)$ & $-0.024(0.096)$ & $-0.084(0.116)$ \\
\hline $\begin{array}{l}\text { Health problems } \\
(t-1)\end{array}$ & $0.016(0.053)$ & $0.112 * *(0.054)$ & $-0.053(0.063)$ & $0.141 * *(0.066)$ \\
\hline $\begin{array}{l}\text { No. of children } \\
(t-1)\end{array}$ & $0.101 * * *(0.033)$ & $0.051(0.037)$ & $-0.001(0.040)$ & $0.026(0.041)$ \\
\hline Renter $(t-1)$ & $0.143 * *(0.072)$ & $0.267 * * *(0.090)$ & $0.197 * *(0.099)$ & $0.070(0.131)$ \\
\hline $\begin{array}{l}\text { Medium firm } \\
(t-1)\end{array}$ & $-0.018(0.069)$ & $-0.109 *(0.066)$ & $0.077(0.096)$ & $0.123(0.091)$ \\
\hline $\begin{array}{l}\text { Large firm } \\
(t-1)\end{array}$ & $-0.089(0.074)$ & $-0.299 * * *(0.079)$ & $0.209 * *(0.095)$ & $0.150(0.101)$ \\
\hline $\begin{array}{l}\text { Regional } \\
\text { dummies }(t-1)\end{array}$ & Yes & Yes & Yes & Yes \\
\hline Constant & $-2.151 * * *(0.452)$ & $-3.723 * * *(0.420)$ & $-2.551 * * *(0.537)$ & $-1.848 * * *(0.641)$ \\
\hline Pseudo $R^{2}$ & 0.076 & 0.107 & 0.096 & 0.117 \\
\hline
\end{tabular}

mainly because it offers the opportunity to carry out more intrinsically satisfying work. Higher wages or better extrinsic rewards are not the driving force behind the transition. In fact, our results show that higher extrinsic rewards in the public sector crowd out intrinsic motivation.

In order to examine whether these patterns of results are unique for transitions from the private to the public sector, we also estimate transition equations from the public into the private sector. These results, shown in table 4, suggest that the satisfaction with the 
Table 5

Probit Results for Transition-Caring and Noncaring Jobs (Men and Women)

\begin{tabular}{|c|c|c|}
\hline & \multicolumn{2}{|c|}{ Public } \\
\hline & Caring & Noncaring \\
\hline$\hat{y}_{i t}$ & $-1.343(0.834)$ & $-1.123(0.734)$ \\
\hline$\hat{s}_{i t(\mathrm{SEC})}$ & $0.084(0.191)$ & $0.048(0.175)$ \\
\hline$\hat{s}_{i t(\text { WORK })}$ & $1.248 * * *(0.390)$ & $1.428 * * *(0.368)$ \\
\hline$\hat{s}_{i t(\text { HOURS })}$ & $-1.168 * * *(0.357)$ & $-1.112 * * *(0.321)$ \\
\hline
\end{tabular}

nature of the work itself differential is insignificant for both men and women. This means that individuals are not moving into the private sector because of higher predicted intrinsic rewards, which is in sharp contrast with the results for the transitions into the public sector. This especially true in the case of women, with transitions into private sector jobs driven by extrinsic rewards, such as predicted real earnings and satisfaction with working hours differentials, rather than intrinsic rewards which were the driving factor behind transitions into the public sector. ${ }^{11}$

Table 5 summarizes probit estimation results for transition into caring and noncaring jobs in the public sector. ${ }^{12}$ The results show that the transition probability into both caring and noncaring jobs is more likely when the satisfaction with the nature of the work itself differential increases. These results are consistent with previous empirical findings, which find that public sector workers in noncaring jobs are also intrinsically motivated. For example, Crewson (1997) shows that even public sector engineers (work that has low "caring" characteristics when compared occupations such as teaching or nursing) also show evidence of intrinsic motivation, similar to all other public sector workers. Nevertheless, there is no evidence of crowding out for either caring or noncaring public sector jobs. In table 6, we summarize the results for transitions into different subsectors of the government sector. Interestingly, unlike other central government or local government positions, we find evidence of crowding out in the case of transitions into the National Health Service and higher education sectors only. This is perhaps because these subsectors have a high proportion of caring jobs.

Finally, we test whether the crowding out effect is affected by income. table 7 summarizes the results of transition probabilities for individuals in the lower and upper quartile of earnings prior to the transition. These results suggest that crowding out is evident for low earners, but it is not the case for high earners. However, transitions into the public sector are still driven by satisfaction with the intrinsic aspects of working in the public sector as the

11 Although women in the private sector both earn less and work more hours than women in the public sector (table 3), this does not mean that women switching from the public sector to private sector employment do so because they prefer to work harder for less money. Instead, the results suggest that women move to the private sector from the public sector if they are predicted to earn higher wages and they are predicted to be more satisfied with their hours of work but only at the $10 \%$ confidence level of significance. We indeed acknowledge that the occasional use of a $10 \%$ confidence interval to determine statistical significance is not always warranted given the sample size used in our analysis.

12 These results are from a combined sample of both men and women. 
Table 6

Probit Results for Transition-Government Subsectors (Men and Women)

\begin{tabular}{lccc}
\hline & Central Government & Local Government & NHS and Higher Education \\
\hline$\hat{y}_{i t}$ & $-1.029(0.982)$ & $0.078(0.756)$ & $-2.798 * * *(0.814)$ \\
$\hat{s}_{i t(\mathrm{SEC})}$ & $0.164(0.233)$ & $0.045(0.175)$ & $-0.136(0.190)$ \\
$\hat{s}_{i t(\text { WORK })}$ & $1.299 * *(0.493)$ & $1.325 * * *(0.367)$ & $0.947 * *(0.391)$ \\
$\hat{s}_{i t(\text { HOURS })}$ & $-0.811 *(0.425)$ & $-0.893 * * *(0.334)$ & $-1.395 * *(0.352)$ \\
\hline Note: NHS, National Health Service. The SEs are given in parentheses. \\
"** Indicates significance at a 10\% confidence level, “**” indicates significance at a $5 \%$ confidence level, and “***” indicates \\
significance at a 1\% confidence level.
\end{tabular}

"satisfaction with the nature of the work itself' differential is positive, albeit nonsignificant at conventional levels, at both low and high incomes.

\section{DISCUSSION AND CONCLUSION}

Our findings reveal that extrinsic rewards such as earnings, job security and working hours are either insignificant in influencing the transition probability into the public sector or they exert a negative effect. In contrast, satisfaction with intrinsic rewards increases the probability of transition into the sector. These results provide broad support for the hypothesis that intrinsically or public service motivated employees are attracted to public sector jobs because of a higher satisfaction with the nature of the work itself as the public sector could offer greater opportunities for pro-social or altruistic behaviors. In this case, allowing for sorting between the sectors, one should expect a higher concentration of employees in the public sector who derive high levels of utility from the intrinsic aspects of work, suggesting that person effects are more important than workplace effects in determining the level of intrinsic motivation in the sector.

The person effect approach posits that person (genetic) dispositional effects influence job satisfaction as a trait. This leads to the conclusion that employees are innately satisfied or dissatisfied with the various aspects of their jobs and thus the utility they derive should not change when they quit and move on to new jobs (Arvey et al. 1989; Arvey, Garter, and Buerkley 1991; Cropanzano, James, and Konovsky 1993; Judge and Hulin 1993). ${ }^{13}$ Advocates of the workplace effect approach argue that job characteristics and the working environment in general affect job satisfaction with various job aspects. By and large, specific workplace attributes have a positive or negative influence on specific domain satisfaction measures. Researchers in the related disciplines of organizational behavior, organizational psychology, and human resource management have investigated how job changes affect job satisfaction and how workplace reorganization impacts on the utility individuals derive from various aspects of work (Gerpott 1990; Georgellis and Lange 2007; Nelson, Cooper, and Jackson 1995; Pollard 2001). In this study, we provide evidence that person effects are important determinants of the level of intrinsic motivation in the UK public sector. A potentially fruitful avenue for future research will be to investigate whether workplace characteristics in the public sector influence the level of intrinsic motivation. In 
Table 7

Probit Results for Transition into Public Sector-Income (Men and Women)

\begin{tabular}{lcc}
\hline & Lowest 25 th Percentile $(<£ 910.00 /$ month $)$ & Highest 25th Percentile $(>£ 1833.33 /$ month $)$ \\
\hline$\hat{y}_{i t}$ & $-2.447^{* *}(1.105)$ & $-0.433(1.152)$ \\
$\hat{s}_{i t}(\mathrm{SEC})$ & $0.471^{*}(0.268)$ & $0.017(0.273)$ \\
$\hat{s}_{i t(\text { WORK })}$ & $1.574^{* * *}(0.513)$ & $1.069^{*}(0.589)$ \\
$\hat{s}_{i t(\text { HOURS })}$ & $-1.046^{* *}(0.504)$ & $-0.763(0.488)$ \\
\hline Note: The SEs are given in parentheses. & \\
"** Indicates significance at a 10\% confidence level, “**” indicates significance at a 5\% confidence level, and “***” indicates \\
significance at a 1\% confidence level.
\end{tabular}

this context, a main research question will be whether employees who are not dispositionally inclined to be public service motivated can have their attitudes and beliefs changed by working in the public sector so that they exhibit a higher level of intrinsic motivation. ${ }^{14}$

Our study contributes also to the debate on whether high levels of extrinsic rewards in the public sector could backfire as extrinsic rewards crowd out intrinsic motivation. Previous evidence suggests that crowding out is more likely to occur when performance on a task is difficult to measure as it is the case with many of the jobs in the public sector (Eisenburger, Pierce, and Cameron 1999; Wiersma 1992). Crowding out implies that extrinsic rewards could result in fewer high-quality (highly public service motivated) employees choosing to move to the public sector resulting in a larger than optimal number of extrinsically motivated employees in the sector, with two main undesirable effects. First, it will have a detrimental effect on the average quality of job matches in the sector; and second, by altering the composition of the workforce, it paves the way for the wider acceptance of performance related remuneration schemes and the use of costly, high-powered incentives to improve performance could become inevitable.

The use of high-powered incentives and other forms of extrinsic rewards in the public sector has long been questioned. For example, Holmstrom and Milgrom (1991) argue that if an employee performs several tasks and it is not easy to measure how well these tasks are performed, then introducing explicit extrinsic incentives is not always efficient as such incentives are often associated with less effort and less attention being placed on tasks of high social value. A good example is teaching. Teachers have the choice of whether to invest in effort that will improve the test scores of students or effort that gives students other skills such as inquisitiveness and curiosity whose performance is difficult to measure. Holmstrom and Milgrom (1991) argue that if teachers are given incentive pay based on exam performance then they will exert less of the second type of effort. Thus, the overall outcome of incentive pay may be an undesirable one and it could simply be a first best option to offer teachers a flat salary. How then is it possible to motivate teachers? We believe the answer is to hire teachers who are intrinsically motivated, who will have less incentive to shirk either type of effort. By the same token, reducing earnings and other extrinsic rewards could also improve efficiency and performance, by improving the quality of job matches between intrinsically motivated employees and public sector jobs and by

14 Previous evidence links workplace attributes including rules, procedures, red tape, and/or limited (or negative) client interaction to the erosion of the traditionally prosocial nature and activities of many jobs (see Buchanan 1974a, 1974b, 1975; Vinzant 1998). 
reducing problems of adverse selection in public sector hiring. To put these policy implications into context, it is important to consider the specific nature of the British labor market where public sector employment often pays better than private sector employment.

However, our results support the crowding out/sorting hypothesis only in the case of specific segments of the UK public sector, such as the National Health Service and the higher education sector. We found no evidence of crowding out among caring and noncaring public sector jobs, central and local government, and among the highest paying jobs. Thus, our findings suggest that crowding out effects only occur in certain/limited circumstances. It would be interesting to explore in future work whether these findings can be generalized to public/private sector settings in the United States and in other countries.

Future work needs to also focus on exploring whether the findings in this study can be replicated using alternative measures of intrinsic motivation. Although our findings inform the PSM literature, the use of 'satisfaction with the nature of the work itself' as the main measure limits the scope of the study to exploring intrinsic motivation in the context of the UK public sector, but it does not allow us to isolate prosocial, altruistic, or other-regarding behavior for it to serve as an adequate measure of PSM. Adopting more precise, yet operational, measures of PSM is a promising way forward for a future research agenda. Although much of the success of future work in identifying suitable measures of PSM hinges upon the availability of data, the complexity and the dynamic nature of PSM needs to be addressed both at the theoretical and the empirical level. After all, not all public sector jobs are tied to prosocial activities, which at the very least calls for a more disaggregated analysis, for example, at the three-digit occupational or industrial classification level. At the same time, the rapidly changing face of public services in recent years, in the United Kingdom, and across many industrialized economies, poses the question whether static measures are sufficient to capture the complex nature of PSM as a theoretical construct.

\section{REFERENCES}

Alonso, Pablo, and Gregory Lewis. 2001. Public service motivation and job performance: Evidence from the federal sector. American Review of Public Administration 31:363-80.

Ariely, Dan, Anat Bracha, and Stephan Meier. 2009. Doing good or doing well? Image motivation and monetary incentives in behaving pro-socially. American Economic Review 99:544-55.

Arvey, Richard D., Thomas J. Bouchard, Nancy L. Segal, and Lauren M. Abraham. 1989. Job satisfaction: Environmental and genetic component. Journal of Applied Psychology 74:187-92.

Arvey, Richard D., Gary W. Garter, and Deborah K. Buerkley. 1991. Job satisfaction: Dispositional and situational influences. In International review of industrial organizational psychology, ed. C. L. Cooper and I. T. Robertson. Oxford, UK: Wiley-Blackwell.

Bandura, Albert. 1977. Self-efficacy: Toward a unifying theory of behavioral change. Psychological Review 84:191-215.

Bartol, Kathryn M., and Edwin A. Locke. 2000. Incentives and motivation. In Compensation in organizations: Progress and prospects, ed. S. Rynes and B. Gerhardt, 104-147. San Francisco, CA: Lexington.

Benabou, Roland, and Jean Tirole. 2003. Intrinsic and extrinsic motivation. Review of Economic Studies 70:489-520.

- 2006. Incentives and pro-social behavior. American Economic Review 96:1652-78.

Bender, Keith A. 1998. The central government-private sector wage differential. Journal of Economics Surveys 12:178-220.

Besley, Timothy, and Maitreesh Ghatak. 2005. Competition and incentives with motivated agents. American Economic Review 95:616-36. 
Bretz, Robert, John Boudreau, and Timothy Judge. 1994. Job search behavior of employed managers. Personnel Psychology 47:275-301.

Brewer, Gene A., and Sally Coleman Selden. 1998. Whistle blowers in the federal civil service: New evidence of the public service ethic. Journal of Public Administration Research and Theory 8: 413-40.

Buchanan, Bruce. 1974a. Building organizational commitment: The socialization of managers in work organizations. Administrative Science Quarterly 22:533-46.

- 1974b. Government managers, business executives, and organizational commitment. Public Administration Review 34:339-47.

- 1975. Red-tape and the service ethic. Administration \& Society 6:423-44.

Cadsby, Bram, Fei Song, and Francis Tapon. 2007. Sorting and incentive effects of pay for performance: An experimental investigation. Academy of Management Journal 50:387-405.

Carpenter, Jeffrey, and Caitlin Knowles Myers. 2007. Why volunteer? Evidence on the role of altruism, reputation, and incentives. Institute for the Study of Labor (IZA) Discussion Paper No. 3021.

Christensen, Robert, and Bradley Wright. 2009. The effects of public service motivation on job choice decisions: Exploring the contributions of person-organization fit and person-job fit Presented at the 10th Public Management Research Conference, Columbus, Ohio, October 1-3.

Clark, Andrew, Yannis Georgellis, and Peter Sanfey. 1998. Job satisfaction, wage changes and quits: evidence from Germany. Research in Labor Economics 17:95-121.

Clerkin, Richard M., Sharon R. Paynter, and Jami Kathleen Taylor. 2009. Public service motivation in undergraduate giving and volunteering decisions. The American Review of Public Administration 39:675-98.

Coyle-Shapiro, Jacqueline, and Ian Kessler. 2003. The employment relationship in the UK public sector: A psychological contract perspective. Journal of Public Administration Research and Theory 13: 213-30.

Crewson, Philip. 1997. Public service motivation: Building empirical evidence of incidence and effect. Journal of Public Administration Research and Theory 7:499-518.

Cropanzano, Russell, Keith James, and Mary A. Konovsky. 1993. Dispositional affectivity as a predictor of work attitudes and job performance. Journal of Organizational Behavior 14:595-606.

Croson, Rachel, and Uri Gneezy. 2009. Gender differences in preferences. Journal of Economic Literature 47:448-74.

Deci, Edward L. 1971. Effects of externally mediated rewards on intrinsic motivation. Journal of Personality and Social Psychology 18:105-15.

Deci, Edward, Richard Koestner, and Richard Ryan. 1999. A meta-analytic review of experiments examining the effects of extrinsic rewards on intrinsic motivation. Psychological Bulletin 125:627-68.

Deci, Edward, and Richard Ryan. 1985. Intrinsic motivation and self determination in human behavior. New York: Plenum Press.

Delfgaauw, Josse, and Robert Dur. 2007. Signalling and screening of workers' motivation. Journal of Economic Behavior and Organizations 62:605-24.

- 2008. Incentives and workers' motivation in the public sector. Economic Journal 118:171-91.

Diener, Ed. 2000. Subjective well-being: the science of happiness and a proposal for a national index. American Psychologist. 55: 34-43.

Dilulio, John D. 1994. Principled agents: the cultural bases of behavior in a federal government bureaucracy. Journal of Public Administration Research and Theory 4:277-318.

Dormann, Christian, and Dieter Zapf. 2001. Job satisfaction: a meta-analysis of stabilities. Journal of Organizational Behavior 22:483-504.

Eisenburger, Robert, W. David Pierce, and Judy Cameron. 1999. Effects of reward on intrinsic motivation - negative, neutral, and positive: Comment on Deci, Koestner, and Ryan. Psychological Bulletin 125:677-91.

Feeney, Mary K. 2008. Sector perceptions among state-level public managers. Journal of Public Administration Research and Theory 18:465-94.

Francois, Patrick. 2001. Public service motivation as an argument for government provision. Journal of Public Economics 78:275-99. 
Francois, Patrick, and Michael Vlassopoulos. 2008. Pro-social motivation and the delivery of social services. CESinfo Economic Studies 54:22-54.

Freeman, Richard. 1978. Job satisfaction as an economic variable. American Economic Review 68:135-41.

Frese, Michael, and Doris Fay. 2001. Personal initiative: an active performance concept for work in the 21st century. Research in Organizational Behavior 23:133-87.

Frey, Bruno S. 1992. Tertium Datur: Pricing, regulating and intrinsic motivation. Kyklos 45:161-84.

Frey, Bruno S., and Reto Jegen. 2001. Motivation crowding theory. Journal of Economic Surveys 15:589-611.

Frey, Bruno S., and Felix Oberholzer-Gee. 1997. The cost of price incentives: An empirical analysis of motivation crowding-out. American Economic Review 87:746-55.

Frey, Bruno S., Felix Oberholzer-Gee, and Reiner Eichenberger. 1996. The old lady visits your backyard: A tale of morals and markets. The Journal of Political Economy 104:1297-313.

Gabris, Gerald, and Gloria Simo. 1995. Public sector motivation as an independent variable affecting career decisions. Public Personnel Management 24:33-51.

Georgellis, Yannis, and Thomas Lange. 2007. Participation in continuous, on-the-job training and the impact on job satisfaction: longitudinal evidence from the German labor market. The International Journal of Human Resource Management 18:969-85.

Gerhart, Barry, and Sara Rynes. 2003. Compensation: Theory, evidence, and strategic implications. Thousand Oaks, CA: Sage.

Gerpott, Torsten. 1990. Intracompany job transfers: An explanatory two sample study of the buffering effects of interpersonal support. Prevention in Human Services 8:139-58.

Gneezy, Uri, and Aldo Rustichini. 2000a. Pay enough or don't pay at all. Quarterly Journal of Economics 115:791-810. . 2000b. A fine is a price. Journal of Legal Studies 29:1-17.

Grant, Adam. 2008. The significance of task significance: Job performance effects, relational mechanisms, and boundary conditions. Journal of Applied Psychology 93:108-24.

Gregg, Paul, Paul Grout, Anita Ratcliffe, Sarah Smith, and Frank Windmeijer. 2008. How important is Pro-social behavior in the delivery of public services. Centre for Market and Public Organisations Working Paper 08/197

Guyot, James F. 1962. Government bureaucrats are different. Public Administration Review 22:195-202.

Harrison, David A., Meghna Virick, and Sonja Williams. 1996. Working without a net: Time, performance, and turnover under maximally contingent rewards. Journal of Applied Psychology 81: $331-45$.

Heckman, James. 1979. Sample selection bias as a specification error. Econometrica 47:53-161.

Holmstrom, Bengt, and Paul Milgrom. 1991. Multitask Principal-agent analyses: Incentive contracts, asset ownership, and job design. Journal of Law, Economics and Organization 7:24-52.

Houston, David J. 2000. Public-service motivation: a multivariate test. Journal of Public Administration Research and Theory 10:713-28.

. 2006. "Walking the walk" of public service motivation: public employees and charitable gifts of time, blood, and money. Journal of Public Administration Research and Theory 16:67-86.

Judge, T. A., and C. L. Hulin. 1993. Job satisfaction as a reflection of disposition: a multiple source causal analysis. Organizational Behavior and Human Decision Processes 56:388-421.

Kilpatrick, Franklin, Milton Cummings, and M. Kent Jennings. 1964. The image of the federal service. Washington, DC: Brookings.

Kim, Sangmook. 2005. Individual-level factors and organizational performance in government organizations. Journal of Public Administration Research and Theory 15:245-61.

Lepper, Mark, David Greene, and Richard Nisbett. 1973. Undermining children's intrinsic interest with extrinsic rewards: a test of the "overjustification" hypothesis. Journal of Personality and Social Psychology 28:129-37.

Lewis, Gregory, and Sue Frank. 2002. Who wants to work for the government? Public Administration Review 62:395-404. 
Locke, Edwin A., and D. Henne. 1986. Work motivation theories. In International review of industrial and organizational psychology, ed. C. Cooper and I. Robertson, 1-35. Chichester, UK: Wiley.

Locke, Edwin A., and Gary P. Latham. 1990. Work motivation and satisfaction: light at the end of the tunnel. Psychological Science 1:240-46.

Lynn, Peter. 2006. Quality profile: British Household Panel Survey version 2.0: waves 1 to 13: 1991-2003. Working Paper. Institute for Social and Economic Research, University of Essex.

Lyons, Sean T., Linda E. Duxbury, and Christopher A. Higgins. 2006. A comparison of the values and commitment of private sector, public sector, and parapublic sector employees. Public Administration Review 66:605-18.

Maidani, Ebrahim. 1991. Comparative study of Herzberg's two-factor theory of job satisfaction among public and private sectors. Public Personnel Management 20:441-48.

Mangione, Thomas, and Robert Quinn. 1975. Job satisfaction, counterproductive behavior, and drug use at work. Journal of Applied Psychology 60:114-16.

Mellstrom, Carl, and Magnus Johannesson. 2008. Crowding out in blood donation: Was Titmuss right? Journal of the European Economic Association 6:845-63.

Moynihan, Donald, and Sanjay Pandey. 2008. The ties that bind: Social networks, person-organization value fit, and turnover intention. Journal of Public Administration Research and Theory 18:205-27.

Nelson, Adrian, Cary L. Cooper, and Paul R. Jackson. 1995. Uncertainty amidst change: The impact of privatization on employee job satisfaction and well-being. Journal of Occupational and Organizational Psychology 68:57-71.

Perry, James L. 1996. Measuring public service motivation: An assessment of construct reliability and validity. Journal of Public Administration Research and Theory 6:5-22.

Perry, James L., and Annie Hondeghem. 2008. Motivation in public management: The call of public service. Oxford, UK: Oxford Univ. Press.

Perry, James L., Annie Hondeghem, and Lois Recascino Wise. 2010. Revisiting the motivational bases of public service: Twenty years of research and an agenda for the future. Public Administration Review 70:681-90.

Pollard, Tessa M. 2001. Changes in mental well-being, blood pressure and total cholesterol levels during workplace reorganization: the impact of uncertainty. Work and Stress 15: $14-28$.

Pouliakas, Kostas, and Ioannis Theodossiou. 2009. Confronting objections to performance pay: A study of the impact of individual and gain-sharing incentives on the job satisfaction of British employees. Scottish Journal of Political Economy 56:662-84.

Rainey, Hal G. 1982. Reward preferences among public and private managers: In search of the service ethic. American Review of Public Administration 16:288-302.

1997. Understanding and managing public organizations. San Francisco, CA: Jossey-Bass.

Ryan, Richard, and Edward Deci. 2000. Self-determination theory and the facilitation of intrinsic motivation, social development, and well-being. American Psychologist 55:68-78.

Schneider, Benjamin. 1987. The people make the place. Personnel Psychology 4:437-53.

Simon, Herbert A. 1957. Models of man: Social and rational. Oxford, UK: Wiley.

Steen, Trui. 2006. Public sector motivation: Is there something to learn from the study of volunteerism? Public Policy and Administration 21:49-62.

. 2008. Not a government monopoly: The private, nonprofit, and voluntary sectors. In Motivation in public management: The call of public service. ed. James L. Perry and Annie Hondeghem, 10117. Oxford, UK: Oxford Univ. Press.

Titmuss, Richard. 1970. The gift relationship: From human blood to social policy. London: Allen and Unwin.

Thierry, Henk. 1990. Intrinsic motivation reconsidered. In Work motivation, ed. Uwe Kleinbeck, HansHenning Quast, Henk Thierry, and Hartmut Hacker, 67-82. Florence, Kentucky: Rourledge.

Trevor, Charlie O., Barry Gerhart, and John W. Boudreau. 1997. Voluntary turnover and job performance: Curvilinearity and the moderating influences of salary growth and promotions. Journal of Applied Psychology 75:44-61. 
Tschirhart, Mary, Kira Krital Reed, Sarah J. Freeman, and Alison Louie Anker. 2008. Is the grass greener? Sector shifting and choice of sector by MPA and MBA graduates. Nonprofit and Voluntary Quarterly 37:668-88.

Uhrig, Noah. 2008. The nature and causes of attrition in the British Household Panel Survey. Institute for Social and Economic Research, University of Essex, Working Paper 2008-05.

Vandenabeele, Wouter. 2008. Government calling: Public service motivation as an element in selecting government as an employer of choice. Public Administration 86:1089-105.

Vigoda, Eran, and Aaron Cohen. 2003. Work congruence and excellence in human resource management. Review of Public Personnel Administration 23:192-216.

Vinzant, Janet C. 1998. Where values collide: Motivation and role conflict in child and adult protective services. American Review of Public Administration 28:347-66.

Warner, Lloyd, Paul Van Riper, Norman Martin, and Orvis Collins. 1963. The American federal executive. New Haven, CT: Yale Univ. Press.

Wiersma, Uco. 1992. The effects of extrinsic rewards in intrinsic motivation: A meta-analysis. Journal of Occupational and Organizational Psychology 65:101-14.

Wittmer, Dennis. 1991. Serving the people or serving for pay: Reward preferences among government, hybrid sector and business managers. Public Productivity \& Management Review 14:369-83.

Wright, Bradley. 2007. Public service and motivation: Does mission matter? Public Administration Review 67:54-64.

Wright, Bradley, and Robert Christensen. 2007. Public service motivation: Longitude analysis of job selection and satisfaction Paper presented at the Ninth Public Management Research Association Conference, University of Arizona, Tucson, AZ, October 25-27.

Wright, Bradley, and Sanjay Pandey. 2008. Public service motivation and the assumption of person organization fit: Testing the mediating effect of value congruence. Administration \& Society 40: $502-21$. 